\title{
Apolipoprotein B48 Measurement
}

National Cancer Institute

\section{Source}

National Cancer Institute. Apolipoprotein B48 Measurement. NCI Thesaurus. Code C120629.

The determination of the apolipoprotein B48 present in a sample. 